\title{
Place-based economic development strategy in England: Filling the missing space
}

\section{Paul Hildreth, University of Salford, Manchester and Bartlett School of Planning, University College London ${ }^{1}$ \\ Professor David Bailey, Aston Business School, Aston University}

\begin{abstract}
This paper examines the implications of a place-based economic strategy in the context of the UK Coalition government's framework for achieving local growth and the creation of Local Economic Partnerships in England. It draws on the international literature to outline the basic foundations of place-based policy approaches. It explores two key features, particularly as they relate to governance institutions and to the role of knowledge. After examining key concepts in the place-based policy literature, such as 'communities of interest' and 'capital city' and 'local elites', it shows how they might be interpreted in an English policy context. The paper then discusses a place-based approach towards an understanding of the role of knowledge, linked to debates around smart specialisation. In doing so, it shows why there is an important 'missing space' in local growth between the 'national' and the 'local' and how that space might be filled through appropriate governance institutions and policy responses. Overall, the paper outlines what a place-based approach might mean in particular for Central Government, in adapting its approach towards sub-national places and for local places, in seeking to realise their own potential. Furthermore, it outlines what the 'missing space' is and how it might be filled, and therefore what a place-based sub-national economic strategy might address.
\end{abstract}

Keywords: Place-Based Approaches, Local Growth, Smart Specialisation, Localism, Regional Policy, Industrial Policy, LEPs.

\section{Introduction}

Given that 'the place-based approach is the 'new paradigm' of regional policy' (Barca, 2011: 225), this paper addresses the question: what does a place-based strategy mean for sub-national economic development policy in England? The paper draws on the international literature (e.g. Barca, 2009; OECD, 2009a, 2009b, 2012; Barca et al., 2012) to introduce a modern place-based understanding of the role of institutions for governance and of knowledge, before going on to show why there is an important

\footnotetext{
${ }^{1}$ Corresponding author: Paul Hildreth, Centre for Sustainable Urban and Regional Futures (SURF), University of Salford, Manchester, Joule House, The Crescent, Salford, M5 4WT, UK, P.A.Hildreth@salford.ac.uk
} 
'missing space' between Central Government (the national) and locally based governance institutions (the local) in economic development policy in England. In so doing it discusses how that space might be filled through appropriate institutions and policy responses.

In May 2010, the newly elected Conservative Liberal Democrat Coalition UK government claimed to offer a 'new approach to local growth' (local growth) (HMG, 2010) that would shift power away from central government to local communities. At the centre of this approach, 39 Local Enterprise Partnerships (LEPs) were created through a relatively bottom-up process across England, largely reflecting local partners' perceptions of the natural economy of their area (and/or the real politics of local cooperation). A first round of City Deal agreements was then negotiated by the government with the eight English Core Cities ${ }^{1}$ to make powers and policy levers available to city leaders to enable them to deliver growth and jobs (HMG, 2011). A further round of City Deals is being progressed with more English cities at the time of writing. ${ }^{2}$ The government claims that this approach is place-based in creating a more balanced economy that: "...recognises that places have specific geographic, historic, environmental circumstances that help to determine the prospects for growth and the most suitable approach to support the private sector and residents' opportunities" (HMG, 2010: 7).

But is this policy place-based in practice and does it actually matter? There are limitations in taking the rhetoric (what Ministers and government publications say that a policy is all about) and even the policies at face value (Hildreth and Bailey, 2013). In addition, if local growth was not place-based, then what would be the alternative? In the English context the distinction between place-based and space-neutral (or peoplecentred) approaches have, until very recently, tended to focus on the narrow issue of whether it is better to prioritise investment in place (as place-based) or invest in people (as people-based) (e.g. see Crowley et al., 2012). The issue came to a head as commentators questioned the effectiveness of spatially targeted spending through Regional Development Agencies (RDAs) and other programmes, after more than a decade of active regional and urban policy under Labour. In doing so, they highlighted what they perceived as the limitations of place-based investments (Crowley et al., 2012; Overman and Gibbons, 2011).

The remarkably narrow way in which this debate had largely been conducted in the English context contrasted with the much livelier international debate between proponents of place-based and space-neutral approaches (e.g. see Gill, 2010; Barca and McCann, 2010)). The fact that this was, at least until very recently (e.g. see Peck et al., 2013), largely ignored in the UK focussed policy and academic literature is surprising 
given that the coming round of EU Cohesion Policy from 2014 is founded on a placebased framework (Barca, 2009). It is also central to OECD policy towards regions (OECD, 2009a, 2009b and 2012) and other new evidence and observations about the increasingly heterogeneous nature of the urban system in Western Europe (Dijkstra, 2013; Dijkstra et al., 2013, Parkinson and Meegan, 2013) and the role of institutions (e.g. see Feser, 2013;;Turok, 2013; Tomaney, 2014) in development.

However, examining the implications of a place-based economic strategy in an English context presents a challenge for three reasons. First, as already indicated, governments (both Coalition and former Labour ones) commonly use the rhetoric of place-based policy, even when its policies and economic rationale might not come close to fitting them (Hildreth and Bailey, 2013). Rhetoric like 'rebalancing the economy' (HMG, 2010) might commonly be used by Ministers without substance behind it (Hildreth and Bailey, 2013; Froud et al., 2011a). Second, differences between the place-based and spaceneutral approaches are open to misunderstanding (Barca, 2011). Both start from a primary concern for the welfare of people, are founded on logical economic principles and recognise spatial agglomeration as a reality, but then diverge around different underlying assumptions. Third, some of the differences between the two approaches are not straight forward to comprehend. For example, the place-based approach draws on its own distinctive terminology (e.g. 'communities of interest' and 'local elites' and 'capital city elites') that requires relating to an English context.

This paper considers the implications of a place-based economic strategy for the local growth agenda in England. The paper is organised around in five sections. Section two introduces the foundations of place-based policy approaches, drawing on the international literature. In particular it identifies two key features of a place-based approach, relating to the role of governance institutions and to knowledge in the context of place. Section three examines more closely the role played by national and local governance institutions. It introduces key concepts in the place-based policy literature, such as 'communities of interest' and 'local elites' and 'capital city elites' and shows how they might be interpreted in a UK policy context. Section four explores the role of knowledge within a place-based framework. It shows why there is an important 'missing space' in local growth between the national and the local and how that space might be filled through appropriate institutions and policy responses. The final section reaches conclusions on what the elements of a place-based approach might be in practice for Whitehall as well as for local places and how the 'missing space' might be filled. 


\section{What is a place-based approach?}

Several recent influential publications advocate place-based approaches towards subnational economic policy (Barca, 2009; OECD, 2009a, 2009b, 2012; Barca et al., 2012). Two contrasting images might be used as a basic introduction to distinguish between placed-based and space-neutral (or so-called people-based) approaches. First, the space-neutral world is one where spatial adjustments occur relatively smoothly between levels of equilibrium in response to market-based price and cost signals in an urban system that is both homogenous and predictable. In pictorial terms it might be thought of as being like a smooth free-flowing river system. ${ }^{3}$ The alternative, a place-based world is somewhat different. It is one where the combination of geography, history, culture and institutions create unpredictability, heterogeneity and uncertainty in the urban system and market outcomes. Pictorially, it is more like a river system with large boulders and rapids that cause many disruptions to the natural flow of the market system. ${ }^{4}$

Barca (2011) identifies five different approaches taken towards development policy, to distinguish what is both common and divergent amongst them. ${ }^{5}$ From this analysis there are important lessons which are of relevance for understanding what place-based approaches might mean in a UK/English context.

A challenge is that the case for people-based (or space-neutral) approaches is not always framed in the same way. As Barca points out, a classic report that presents a space-neutral approach based on a particular reading of the New Economic Geography (NEG) framework is the 2009 World Development Report (World Bank, 2009). This draws on a mix of three of the five approaches: a particular emphasis on the role of 'unique' institutions that are designed at a national level; agglomeration driven development; and a market-led approach towards economic redistribution. In a UK context, the case for people-based approaches (e.g. Overman and Gibbons, 2011; Leunig and Swaffield, 2008), puts a stronger emphasis on the role of efficient markets in promoting agglomeration within a NEG type framework (what Barca calls an 'agglomeration driven approach') and a significantly lesser emphasis on the role of 'unique' institutions'.

In addition, it should also be recognised that the distinction between space-neutral and place-based approaches is not really centred on choices between investing in people or places. Both approaches are actually concerned with both people and place. What distinguishes the place-based approach is that it puts greater emphasis on arguing that: 'the well-being of each person... also depends on the context in which he/she lives.' 
(Barca, 2011: 221). At the risk of over-simplification, the core of the argument around place-based approaches essentially boils down to two key hypotheses. These concern the role of knowledge in relation to places and 'local (and national) elites' in institutions for governance that arise out of the significance of the impact of geography, history, culture and institutions to development, as Barca (2011, page 223) highlights:

'The 'place-based' approach argues that no actor knows in advance 'what should be done'. It posits that sensible and reasonable decisions can emerge as the innovative result of a process of interaction and even conflict between endogenous and exogenous forces i.e. between the knowledge embedded in a place and external knowledge. ..it also stresses the role played in producing under-development by the failure of the part of local elites... and their innate tendency to seek rents from public interventions. For these two reasons, the place-based approach.....assigns a much greater role of exogenous institutions - their knowledge, preferences and values - and therefore advocates multilevel governance.'

These two key issues of governance institutions and knowledge and their interaction in the context of place are explored next in the English context.

\section{What is the role of governance institutions in this context?}

We now focus on institutional issues relating to the governance of the national (UK and English policy making in Whitehall) and local dimensions of place-based policy making.

\section{The National}

A place-based framework identifies two potential institutional weaknesses in the national, for it to be aware of, as it conducts sub-national economic policy for England. One is that the national has a tendency to lack both an understanding and knowledge of local places. This is identified in the literature as lacking a 'sense of community', which is a form of social capital that understands the local institutional context in which development takes place (Tabellini, 2010; Barca et al, 2012). It is argued that the national has a consequent weakness in its capacity both to adapt its approach towards local places and mediate local consensus and trust between local actors as well as mobilise local resources effectively (Rodríguez-Pose and Storper, 2006). If the national does not appropriately understand or adapt to this weakness, it might undermine the design and effective conduct of sub-national policy. The other key argument is that the national is prone to the policy-making influence of 'capital city elites' in favouring infrastructure, innovation and sectoral investment for the capital city over other sub- 
national places (Barca et al., 2012). As a result, national policy decisions may divert resources to promote unnatural agglomerations, as well as supporting natural ones.

How might these arguments be relevant to UK government departments in London (Whitehall)? It appears that there are key reasons why, as Heseltine (2012) points out, Whitehall might have a built-in tendency towards addressing economic issues in a placeless or space-blind context. This is despite its active use of place-based language. Some key reasons why this might be a problem is summarised in the following paragraphs.

First, there is a long-standing culture of centralism in the UK and particularly so in England (Heseltine, 2012). 'Conditional localism' can be defined as a commitment by the national to delegate to the local that is conditional on the local supporting the national's policy objective and/or performance priorities and standards. As a consequence, the priorities of the local are driven as much by the demands of the national as by the aspirations of the local to serve its communities (Hildreth, 2011). ${ }^{6}$ Despite the government's rhetoric of localism, very little has substantially changed in the distribution of powers between the national and local under the Coalition. Furthermore, historically, at the first sign of trouble or when the opportunity so arises, historically powers have tended to be taken back into Whitehall, illustrated by the recentralisation of RDA functions back into the Department of Business and Innovation, following their abolition.

Second, the culture of 'conditional localism' (Hildreth, 2011) is well entrenched in England. Arguably, England has shifted from a 'conditional' model enforced through topdown inspection and performance regimes put upon the local by Whitehall under Labour, to one enforced through increasing austerity imposed by the national on the local in constraining the ability of the local to raise financial resources locally at the same time as imposing major cuts in central funding to local authorities (Featherstone et al, 2012). The picture in England can be compared with the 'representative localism' model, closer to a Western European approach founded on strong local leadership and a clear and sometimes constitutional separation of powers and responsibilities between the national and the local. The language of a 'conditional' approach can be seen for example in 'Cities' (HMG, 2011), where cities rather than Whitehall, are identified as the potential barrier to effecting change, whereas there are clear examples where pioneering cities in England led and the national followed (e.g. Manchester and Leeds in relation to urban renaissance and Leicester in energy management) (e.g. see Hildreth, 2013; Hildreth and Bailey, 2013).

Third, Whitehall lacks a holistic perspective of 'place' (Heseltine, 2012; Marvin and May, 2003). Whitehall is organised around themed policy departments, which in turn are 
shaped around functions that focus largely on space-neutral initiatives that are centred on policy specifics. As Heseltine points out, with this fragmentation, no one is tasked to look holistically at the full range of issues facing particular places (Heseltine, 2012). This culture is reflected in the National Policy Planning Framework (DCLG, 2011), which unusually for a Western European country offers a largely un-spatial approach to spatial planning. By focusing on principles and policies to secure 'sustainable development', it has nothing specific to say on the particular contribution that places e.g. Northern England cities and city-regions, might contribute to the 'sustainable development' of England as a whole. In a UK context, this approach might be contrasted with the National Planning Framework for Scotland, which is much more specific in highlighting the importance of places in achieving prosperity (The Scottish Government, 2009).

Fourth, Whitehall operates around, in development terms, short-term policy cycles, geared around electoral cycles of up to five years. These are subject to frequent institutional and policy changes reflecting the policy priorities of the current administration. For example, the current Coalition government swept away regional institutions with little concern or regard for how institutional learning, knowledge and experience in regions had been developed and how it might be retained. No apparent consideration was given to the longer-times scales involved in the economic, social and environmental transition of places and in particular the importance of embedding institutional learning, investment and development over the longer-term. This might possibly reflect blindness in Whitehall to this being a really important issue in the development of places (Hildreth, 2013).

Fifth, retaining institutional memory about place might be a challenge in Whitehall. Particular value is given to general policy-making expertise in response to the immediate political requirements of the governing administration, with frequent movement of civil servants between roles. It might be postulated that this might be a factor in why the value of local context is under-valued in Whitehall.

Sixth, a longer-term process of hollowing-out of the national is now reinforced by continuing austerity cuts on departments. Yet proposals to reform the Civil Service fail to address how Whitehall might engage more strategically with sub-national places with more limited resources or devolve responsibilities to the 'local' (HMG, 2012).

Seventh, the 'national' economic framework is largely un-spatial. In government, the long-standing neo-classical economic framework reinforces the dominance of a spaceneutral perspective that is clouded in an apparently place-based rhetoric (Hildreth, 2009; Hildreth and Bailey, 2013; Froud et al., 2011a). It also constrains Whitehall's openness 
to new evidence; challenging its validity if it does not conform to the parameters of its own favoured framework.

Finally, London (and the Greater South East (GSE) and its banking and financial sector) is given undue influence in policy and resource allocation. London is prioritised at all costs, against other places and sectors, with London provided with a unique model of government in England not on offer elsewhere and prioritisation in public sector investment. A recent IPPR (2013) analysis of transport infrastructure spending illustrated the scale of this disparity, which equated to $£ 2,731$ per person in London and the South East compared with just $£ 5$ per person in the North East. Of the largest 81 transport projects, three-quarters of those in London and the South East had been confirmed and started, compared with just under half elsewhere. This disparity is also revealed in the distribution of Arts Council funding, as reported in the Independent on $3^{\text {rd }}$ July $2013 .^{7}$ Grant in aid per head to London was $£ 21.33$ per head of population in 2011/12 compared with $£ 5.59$ in the North East and $£ 3.51$ in the North West. However, once philanthropic donations are taken into account, the divide becomes even greater, with more than two thirds of donations to cultural organisations in England going to London in 2010 to2011. As a result, statements regarding the spatial and sectoral 're-balancing' of the economy appear empty 'rhetoric' (Froud et al, 2011a). For these reasons, the reform of the national, particularly to develop a more holistic understanding of sub-national places and offer a strategic framework that leads and incentives stronger trusting relationships with the local, may therefore be a key factor to a place-based approach being developed in England.

\section{The Local}

However, this would need to go alongside changes in the local. As noted, place-based approaches highlight the possibility of 'under-development traps' occurring that may inhibit the growth potential of regions and localities or perpetuate the presence of social exclusion (Barca, 2009; Barca et al., 2012). These may be caused by a failure by 'local elites' to act effectively or due to local institutional weaknesses (Barca, 2009).

There may be two sets of problems. Each may arise out of different understandings of place. Place is a dynamic concept. It is the subject of an extensive literature with a diverse range of meanings (e.g. see Hubbard and Kitchins, 2011). A challenge for economic geography is that places do not stand still. Places are not islands, but relate with other places around them through the flows, movements and interactions of people and firms (Hildreth, 2007). Their present context is shaped by history, geographical and social setting and institutional characteristics, making each place distinctive and different 
(Barca et al, 2012). As we have already seen, a key difference between a place-based and a space-neutral approach is whether this really matters for the design of policy.

A set of problems might relate to an understanding of place that relates to 'how we are governed'. This relates to the area administered by the (city or town) local authority. Indeed, this concept of place has particular significance within the Coalition's localism agenda in England (Hildreth, 2011). It is important, because it is usually associated with the civic, cultural and historical identity of the place, which is shaped by events and transitions over very long periods of time. These may impact on the effectiveness of 'local elites' (local authorities and their partners) to enable effective change. This has implications about how the city sees itself and its relationships with other places around it, for example, politically in matters of 'trust', 'control' and 'respect' of its neighbours (Tabellini, 2010).

For example, there might be a lack of trust linked to long-standing historical rivalries between places that lie within the same 'natural economy' that are acted out by political leaderships through lack of effective cooperation across boundaries. In addition, where a city is seriously under-bounded in relation to its physical footprint, it may constrain its capacity to act strategically in relation to its economic area, particularly if there is an absence of trust between neighbouring authorities. A few English city local authorities are so well bounded to capture part of their economic area, beyond the physical footprint of the city. Leeds is one example (see figure one). However, many are well underbounded, such as Nottingham (see figure two). Finally, in the context of a dominant culture of 'conditional localism' in England, there is constant pressure on the local to conform to the demands and priorities of the national over local needs and priorities. This may stifle local innovation and lead to a misappropriate allocation of local resources in relation to local development needs (Hildreth, 2011).

\section{Figure One goes here}

\section{Figure Two goes here}

Furthermore, some of these weaknesses relate to an economic understanding of place, which is defined by 'how we live and work'. It might be referred to as the 'natural economic area' (HMG, 2010), or sub-region, or in appropriate cases, city-region. Yet there are different ways of understanding a 'natural economic area' (HMG, 2010), as it is 
a fuzzy concept. In most cases the appropriate geography of a LEP in England has been interpreted more narrowly rather than broadly. A total of 39 LEPs have been created, some based on limited sub-regional geographies, sometimes influenced by who partners get on with or not, rather than any systematic economic analysis of spatial economies (e.g. Greater Birmingham and Solihull LEP) (See Bentley et al., 2010). Also, the idea of a 'natural economy' based on labour markets has limitations outside the bigger city agglomerations. It works well for Manchester and Leeds, where there clearly is a cityregional geography. But for 'gateway' cities like Hull, and 'industrial' cities like Blackburn and Burnley (Hildreth, 2007a), the geography of their labour markets is contained within a limited space and their economies 'isolated' in relation to other places (e.g. see Work Foundation, SURF and Centre for Cities, 2009). This undermines the value of a 'natural economy', as a loosely used concept. Further, the geography of firms, for example in supply chain relationships may go far wider than that captured by travel to work areas. The relevant economic scale for the automotive cluster, for example, covers at least five English regions (the East Midlands, North West, South East and the West Midlands) (Hildreth and Bailey, 2013).

The consequential outcome is likely to be a widening institutional capacity gap between places in responding to the challenges of their local economies. Leeds and its partners have been building city-regional capacity since the early 2000s and were able to absorb the 'best' features of the new LEP (such as gaining the input of able private sector leaders new to working with the public sector) to develop further (see Hildreth, 2013). Contrast this with the North East LEP area. Despite encouragement from the 2006 OECD Territorial Review to form effective city-regional collaboration (OECD, 2006), the local authority partners found it difficult to maintain progress due to lack of trust historically partially, but not wholly, between Newcastle and Sunderland. Following the 2010 general election, momentum was initially lost by disbanding city-regional structures in the aftermath of the abolition of the Regional Development Agency, One NorthEast, in the aftermath of the election of the Coalition government. However, the recently formed North East LEP partners have been working hard to catch up, having commissioned an Independent Economic Review and by the local authority partners developing and consulting on proposals to form a Combined Authority from April 2014. Nevetheless, the process of reaching this point has not been at all easy.

So under a place-based perspective, institutional weaknesses might be identified in both the national and the local, which potentially act as barriers to the successful realisation of the potential of different places. Part of the answer in a place-based framework is to develop a multi-level governance (MLG) framework to bridge the national and the local. The significance of such an MLG approach is not that it is just public to public, but rather 
so that different actors - public and private - inter-dependently contribute towards the success of the sub-national economy. However, within this gap between the national and the local there is a 'missing space' that at the present time neither fills adequately.

\section{The 'missing space' and the role of knowledge in a place-based approach}

As the end of the previous section began to introduce, there is a 'missing space', between the national and the local which present policy in England fails to address. This 'missing space' occurs for at least three reasons, particularly outside the larger cityregions (such as Manchester and Leeds). First, because the local (including the LEP), often lacks sufficient scope, depth and capacity to be effective. Linked to this, there is the risk that local elites may capture policy and funding for their own benefit, so exogenous challenge is required. Second, outside the larger city-regions, LEPs commonly lack appropriate geography (Hildreth and Bailey, 2013; Heseltine, 2012). Third, there remains the absence of effective MLG, offering mature and trusting relationships between the national and the local. Few might argue for going back to the top-down administrative geography of RDAs, but given the fragmentation and significant capacity variation in the subsequent LEPs created in a bottom-up way, a critical question arises: is there a 'missing space' that present policy does not fill and does it matter?

Under a space-neutral framework none of this would seem to matter as such industrial and regional policy interventions are perceived to be of limited value. Rather, under a space-neutral approach, key elements of policy should instead focus on: supporting disadvantaged people to achieve better individual outcomes, through education, skills and welfare policy, regardless of where they live; enabling greater geographic mobility to make it easier for people to move to growing areas; and reducing the barriers to the expansion of economically successful places (Overman and Gibbons, 2011). The basic argument is that left to themselves, markets will adjust if the barriers preventing them doing so are addressed. Hence, from this perspective, it is more important to focus on what are referred to 'horizontal' interventions, such as skills policy and reducing red tape, that operate in a space-neutral way (Nathan and Overman, 2013), rather than seeking to fill a 'missing space' with targeted institutionally based or related solutions. However, giving local authorities greater local discretion is supported to some extent, because it facilitates experimentalism and innovation.

A place-based approach sees things differently. In part this is because knowledge about places is seen as critical for effective policy development (Barca et al., 2012; Barca, 2011). In a heterogeneous urban system, where the combination of geography, history, culture and institutions creates uncertainty, such knowledge is not already known either 
by the state, firms or local stakeholders. As a result there is a positive role for policy in aiming to stimulate new knowledge and ideas through interactions between local groups (endogenously) and external actors (exogenously) (ibid). Linked to this, the 'smart specialisation' approach has been closely linked with place-based approaches to regional development policy, at least in Europe (Barca, 2009; European Commission, 2011). In regional policy terms it has emphasised the need to exploit related variety, build regional embeddedness and enable strategic diversification (McCann and Ortega-Argilés, 2011, 2013). In so doing, it stresses the need for regional actors (government, firms, universities, research institutions) to collaborate, recognising the current starting point for the region in terms of skills, technologies and institutional governance and then to build on these capabilities rather than trying to start 'from scratch' (Barca et al, 2012).

This place-based smart specialisation approach has parallels with perspectives on industrial policy as a process of discovery requiring strategic collaboration between the private sector and state in unlocking growth opportunities (see Rodrik, 2008), but set within an MLG framework. So industrial and regional policies which facilitate this process of discovery through strategic collaboration are seen as relevant and require appropriate institutions to engender this. But in this regard, there is a noted institutional and capacity failure at the national level in England through the lack of resources to design industrial policy interventions (see Froud et al, 2011b, page 20). Given the capacity constraints of many LEPs outside of major cities, there would therefore appear to be a role for an intermediate tier in terms of industrial and regional policy development (see IPPR and Northern Economic Futures Commission, 2012).

An interesting question here is to what extent Whitehall has responded to the recommendations of the Heseltine (2012) report and is prepared to change so as to allow this 'missing space' to be filled. ${ }^{8}$ While the government announced they are "accepting in full or in part 81 of Heseltine's 89 recommendations", the reality is less encouraging as a detailed examination of Annex A of the government response (HMTreasury, 2013) indicates. Marlow (2013), for example shows that of the 15 Heseltine proposals relating to 'local growth deals', the government 'accepts' just nine of them. Furthermore, the 'Single Pot' funding announced in the 2013 Spending Review (HMT, 2013a) for 2015-16 in response to Heseltine was minimal, at just $£ 2 b n$. This was less than the $£ 3 b n$ expected by many commentators, and fell well short of what the Centre for Cities (2013) saw as a minimum need of $£ 5 \mathrm{bn}$ a year with more powers for cities to invest in their own local economies (Bailey, 2013). 


\section{Conclusion: what does this mean for Local Growth in England?}

Using this analysis adds value to the policy debate in the English context as it highlights that in a place-based framework, institutional weaknesses can be identified in both the national and the local, which potentially act as barriers to the successful realisation of the potential of different places. Indeed, part of the policy solution in a place-based framework is to develop a MLG framework to bridge the national and the local. For the national it is about recognising its weaknesses - in particular both its inability to make sound judgements appropriate to local context and its limited ability to foster the engagement of local stakeholders (public or private) to drive economic development. Yet it also has an important role to foster trust between the national and local. This is in the design of the devolution of responsibilities and resources to maximum effect, to offer a strategic view on realising the potential contribution of different places to national prosperity and to incentivise collaborative behaviours. For the local it is about seeking an exogenous input to support locally based collaboration to enable the targeting of places with appropriate bundles of public good investments and overcoming issues of trust that may operate locally between different places. The significance of the MLG approach is not that it is just public to public, but rather that in a place-based framework, different actors - public, private and third sector - inter-dependently contribute towards the success of the sub-national economy and have different roles to play. In that context, much of the action and collaboration may take place in what we perceive as the 'missing space', between the 'national' and the 'local' which present policy (in England at least) does not fully address.

Filling this 'missing space' requires regionally-based industrial development strategies which recognise (i) the need to bring together different but related activities in a region and (ii) the differing potentials of regions to diversify, due to different industrial, knowledge and institutional structures arising out of specific regional histories. Such an approach also recognises that knowledge is not already known either by the state, firms or local stakeholders, so there is a positive role for regional and industrial policies in aiming to 'discover' or stimulate new knowledge and ideas through interactions between local groups (endogenously) and external actors (exogenously). Rather than 'starting from scratch' or applying 'one size fits all policies', regional industrial strategies require tailor-made policy actions embedded in, and linked to the specific needs and available resources of regions, starting with the existing knowledge and institutional base in that region. These need to capitalise on region-specific assets, rather than attempting to apply policies that may have worked in quite different places. Moreover, such place- 
based institutions and interventions need to overcome potential weaknesses that operate at and between the national and local. This, we argue, has yet to be realised in the English context.

\section{Bibliography}

Bailey, D (2013). 'Yes Minister' style scrap going on over Heseltine Plan for Devolution', The Regional Studies Blog. Available at: http://www.thersablog.com/2013/06/yesminister-style-scrap-going-on-over.html (last accessed 9 December2013).

Barca, F (2009) An Agenda for a Reformed Cohesion Policy: a Place Based Approach to Meeting European Union Challenges and Expectations, Brussels: DG Regio.

Barca, F (2011) Alternative Approaches to Development Policy: Intersections and Divergences, in OECD, OECD Regional Outlook 2011, 215-225, Paris: OECD publishing.

Barca, F and McCann, P (2010) The Place-based Approach: A Response to Mr Gill, VoxEU.org, $9^{\text {th }}$ October. Available at http://www.voxeu.org/article/regionaldevelopment-policies-place-based-or-people-centred (last accessed on 6th December 2013)

Barca, F, McCann, P and Rodríguez-Pose, A (2012) The Case for Regional Development Intervention: Place-based Versus Place-neutral Approaches, Journal of Regional Science, 52(1):134-152.

Bentley, G, Bailey, D and Shutt, J (2010) From RDAs to LEPs: A New Localism? Case Examples of West Midlands and Yorkshire, Local Economy, 25(7): 535-557

Centre for Cities (2013) Disappointment or Devolution? The Spending Review and Heseltine's Single Local Growth Fund. Available at:

http://www.centreforcities.org/assets/files/2013/13-06-25-Devolution-ordisappointment.pdf (last accessed 9 December 2013)

Crowley, L, B Balaram and N lee (2012) People or Place? Urban Policy in the Age of Austerity. London: The Work Foundation.

Department for Communities and Local Government (DCLG) (2012) National Planning Policy Framework, DCLG, London. Available at:

https://www.gov.uk/government/uploads/system/uploads/attachment data/file/6077/21 16950.pdf (last accessed on 10 December, 2013) 
Dijkstra, L (2013) Why Investing More in the Capital Can Lead to Less Growth, Cambridge Journal of Regions, Economy and Society, 6(2):251-268.

Dijkstra, L, Garcilazo, E and McCann, P (2013) The Economic Performance of European Cities and City Regions: Myths and Realities, European Planning, 21 (3):334-354.

European Commission (2011) Proposal for a regulation of the European Parliament and of the Council, COM (2011) 615 Final, 6/10/2011,Brussels, European Commission, available online at: http://eur-

lex.europa.eu/LexUriServ/LexUriServ.do?uri=COM:2011:0615:FIN:EN:PDF (last accessed on $6^{\text {th }}$ December 2013)

Featherstone, D, Ince, A, Mackinnon, D, Strauss, K and Cumbers, A (2012) Progressive Localism and the Construction of Political Alternatives, Transactions of the Institute of British Geographers, 37(2): 177-182.

Feser, E (2014) Planning local economic development in the emerging world order, Town Planning Review, 85(1):19-38

Froud, J, Johal, S, Law, J Leaver, A and Williams, K (2011a) Rebalancing the economy (or buyer's remorse), CRESC Working Paper no. 87, CRESC, Manchester University Available at: http://www.cresc.ac.uk/publications/rebalancing-the-economy-or-buyersremorse (last accessed on 9 December 2013)

Froud, J, Johal, S, Law, J Leaver, A and Williams, K (2011b) Knowing what to Do? How not to Build Trains. CRESC Research Report. CRESC, Manchester University. Available at: http://www.cresc.ac.uk/publications/knowing-what-to-do-how-not-to-build-trains (last accessed on 9 December 2013)

Gill, I (2010) Regional Development Policies: Place-based or People-centred?, VoxEU.org, $9^{\text {th }}$ October. Available at (last accessed 20 February 2013). Available at: http://www.voxeu.org/article/regional-development-policies-place-based-or-peoplecentred

Heseltine M (2012) No stone unturned in the pursuit of growth, London: BIS. Hildreth, P A (2007) The Dynamics of 'Place-shaping': the Changing Rationale for Urban Regeneration, Journal of Urban Regeneration and Renewal, vol. 1, no. 3, pp. 227-239. 
Hildreth, P A (2009) Understanding 'New Regional Policy': What is Behind the Government's Sub-national Economic and Regeneration Policy for England?, Journal of Urban Regeneration and Renewal, 2(4):318-336.

Hildreth P (2011) What is Localism, and What Implications Do Different Models Have for Managing the Local Economy?, Local Economy, 26(8): 702-714.

Hildreth P (2013) Comparative Urban Futures: Spatial Networks for Sustainable Urban Development, MISTRA Urban Futures Manchester Working Paper. Available at: http://ontheplatform.org.uk/article/comparative-urban-futures-spatial-networkssustainable-urban-development (last accessed on 10 December, 2013)

Hildreth, P and Bailey, D (2013) The Economics Behind the Move to 'Localism' in England, Cambridge Journal of Regions, Economy and Society, 6(2):233-249 HM Government (HMG) (2010), Local Growth: Realising Every Place's Potential, Cm 7961, London: Department of Business Innovation and Skills.

HM-Government, Unlocking Growth in Cities (HMG, 2011). Available at: http://www.communities.gov.uk/publications/regeneration/growthcities (last accessed 10 December, 2013)

HMG (2012) The Civil Service Reform Plan, London: Civil Service.

HM-Treasury (2013) Government's Response to the Heseltine Review, London: HMTreasury.

HM-Treasury (2013a) Investing in Britain's Future, Cm 8669, London: HM-Treasury.

HM-Treasury, BERR and CLG (2007) Review of Sub-national Economic Eevelopment and Regeneration, London: HM-Treasury.

HM-Treasury, DTI and ODPM (2006) Devolving Decision Making: 3 - Meeting the Regional Economic Challenge: the Importance of Cities to Regional Growth, London: HMTreasury

Hubbard, P and Kitchin, R (ed.) (2011 $2^{\text {nd }}$ edition) Key Thinkers in Space and Place, London: Sage

IPPR and the Northern Economic Futures Commission (2012) Northern Prosperity is National Prosperity: a Strategy for Revitalising the UK Economy, London: Institute for Public Policy Research. 
IPPR (2013) Still on the Wrong Track: an Updated Analysis of Transport Infrastructure Spending, IPPR North, available at

:http://www.ippr.org/images/media/files/publication/2013/06/still-on-the-wrongtrack June2013 10933.pdf (last accessed 6 ${ }^{\text {th }}$ December 2013)

Leunig, T and Swaffield, J (2008) Cities Unlimited: Making Urban Regeneration Work, Policy Exchange, available at:

http://www.policyexchange.org.uk/images/publications/cities\%20unlimited\%20\%20aug\%2008.pdf (last accessed 9 December 2013)

Marlow, D (2013) Is there a Big Hole in the Innovation 'Stone' in the Government's Response to Heseltine? Regeneration \& Renewal, 25 March 2013.

Marvin, S and May, T (2003) City Futures: Views from the Centre, Cities, 17(2):213-226.

McCann, P and Ortega-Argilés, R (2011) Smart specialisation, regional growth and applications to EU cohesion policy, Economic Geography Working Paper 2011, Faculty of Spatial Sciences, University of Groningen, available online at:

http://www.rug.nl/staff/p.mccann/mccannsmartspecialisationandeucohesionpolicy.pdf (last accessed 9 December 2013)

McCann, P and Ortega-Argilés, R (2013) Transforming European regional policy: a results-driven agenda and smart specialization, Oxford Review of Economic Policy, 29 (2):383-404

Nathan, M and Overman, H (2013) Agglomeration, Clusters and Industrial Policy, Oxford Review of Economic Policy, 29(2): 405-431

OECD (2009a) How Regions Grow: Trends and Analysis, Paris: OECD.

OECD (2009b) Regions Matter: Economic Recovery, Innovation and Sustainable Growth. Paris: OECD.

OECD (2012) Promoting Growth in All Regions. OECD: Paris.

Overman, H G and Gibbons, S (2011) Unequal Britain: how real are regional disparities?, CentrePiece, 16(2)23-25.

Parkinson, M and Meegan, R (2013) Economic place making: policy messages for European cities, Policy Studies, 34(3):377-400. 
Peck, F, Connolly, S, Durnin, J and Jackson, K (2013) Prospects for 'Place-based' Industrial Policy in England: the Role of Local Enterprise Partnerships, Local Economy, 25(7-8):828-841

Rodríguez-Pose, A and Storper, M (2006) Better rules or stronger communities? On the social foundations of institutional change and its economic effects, Economic Geography, 82(1):1-25.

Rodrik, D (2008) One Economics, Many Recipes: Globalization, Institutions, and Economic Growth. Princeton: Princeton University Press.

The Scottish Government (2009) National Planning Framework for Scotland 2, The Scottish Government, Edinburgh. Available at:

http://www.scotland.gov.uk/Resource/Doc/278232/0083591.pdf (last accessed on 10 December, 2013)

Tabellini, G (2010) Culture and institutions: economic development in the regions of Europe, Journal of the European Economic Association, 8(4):677-716

Tomaney, J (2014) Region and place 1: institutions, Progress in Human Geography, 38(1)131-140

Turok, I (2013) People-based versus place-based policies: the 2009 World Development Report, 28(1):3-8

Williams, K. (2012) What Lord Heseltine doesn't say about the Regions, The Guardian, 31/10/2012. Available at: http://www.guardian.co.uk/commentisfree/2012/oct/31/lordheseltine-britain-ex-industrial-regions Last accessed 9 December 2013

World Bank (2008) World Development Report 2009: Reshaping Economic Geography, Washington DC: World Bank

The Work Foundation, SURF, and Centre for Cities (2009), City Relationships: economic linkages in Northern City Regions. Newcastle: The Northern Way

\footnotetext{
${ }^{1}$ Birmingham, Bristol, Leeds, Liverpool, Manchester, Newcastle, Nottingham and Sheffield

${ }^{2}$ As of 8 April 2014, second round City Deals had been announced for LEP areas centred around Black Country, Cambridgeshire, Greater Brighton, Greater Norwich, Hull and Humber, Ipswich, Leicester and Leicestershire, Oxford and Oxfordshire, Plymouth and South West Peninsula, Preston, Southampton and Portsmouth, Southend-on-Sea, Stoke on Trent and Staffordshire, Sunderland, Tees Valley and the Thames Valley (Reading)
} 
${ }^{3}$ The authors would like to thank Professor Philip McCann for this metaphor of a river system to illustrate the differences in approach between a place-based and space-neutral economic system.

${ }^{4}$ Extending the metaphor, even if removing obstructions to the smooth flowing of the river was in theory an appropriate course of action, it cannot be undertaken too quickly as this could cause a sudden surge, and anyway the sequencing of removing barriers (or deregulation) becomes critical.

${ }^{5}$ The five approaches are: (1) Perfect institutions - that good institutions (e.g. education, health, labour markets etc) are a primary driver of growth and that the state knows best what they are and their effectiveness is not context (or place) dependent;

(2) Agglomeration - that agglomeration is a primary driver of growth, as well as a recognition that development requires appropriate institutions and investment suited to what set of unique optimal set of agglomerations that market forces may uncover; (3) Redistributive - that agglomeration not only brings efficiency but also social exclusion and the response is either a market-oriented approach by those who are constrained in approaches towards redistribution through belief in an optimal set of agglomeration outcomes or a softer redistributive approach by those who believe on the contrary that the world is flat; (4) Communitarian - that local awareness of their own knowledge and preferences is the primary driver of development and that development is the result of a local deliberative process and (5) Place-based approaches. Barca argues that there are both intersections and divergences in these different approaches.

${ }^{6}$ Hildreth (2011) sets out a framework for understanding localism based on three models: 'representative localism', 'conditional localism' and 'community localism'. The 'representative localism' model is closer to a Western European approach based on strong local leadership and upholding the principles of the European Charter of Local Self-Governance. The 'conditional localism' model reflects a position where the centre's decentralisation is conditional on the more local body supporting the national policy objectives and/or performance priorities and standards, a situation more akin to the UK situation, particularly under the Labour Government (1997-2010). 'Community localism' involves decentralisation to communities often bypassing local government in the process. There are two models; one where the 'national' delegates responsibility to a local level, but retains overall oversight or control ('commissioning') and the other where control of the asset or service is devolved entirely to a local community ('community asset') who form their own legal vehicle .

${ }^{7}$ See Independent Newspaper on 3 July, 2013 reporting on figures obtained from the Department of Culture, Media and Sport through a written parliamentary question: "As spending cuts bite, regional arts left with London's crumbs', available at:

http://www.independent.co.uk/arts-entertainment/art/news/regional-arts-left-withlondons-crumbs-as-spending-cuts-bite--warns-harriet-harman8684010.html?origin=internalSearch

\section{Acknowledgements}

The authors would like to thank the anonymous referees and guest editors for their very helpful and constructive comments on draft versions of this paper. 
[For Editor: Please note that both Figures One and Two should have a footnote which reads:

Diagram drawn by P Hildreth and published within HMT, DTI and ODPM (2006))]

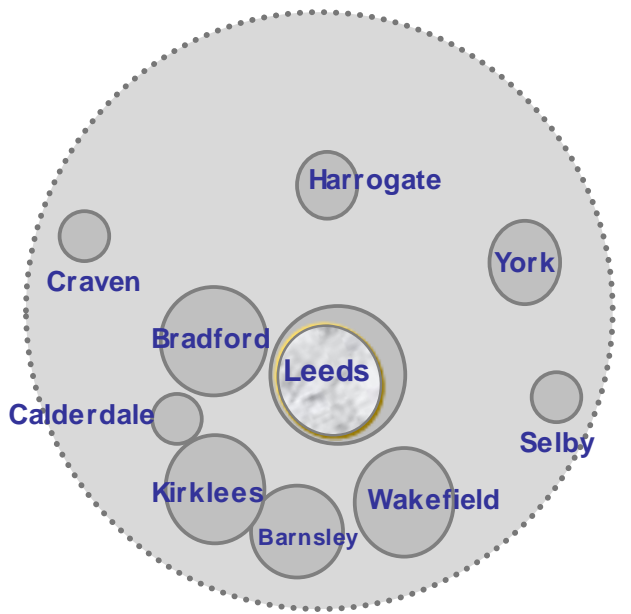

Leeds is a classic example of a wellbounded city. The City Council has a remit ov er and bey ond the whole of the contiguous built up area of Leeds.

Leeds has a relativ ely large and successful economy, with a signif icant economic footprint shown by its wide trav el-to-work area. It is a major UK centre for finance, legal and business services. Howev er, the long term success of the Leeds economy requires the capacity to capture the larger economic scale and the sharing of assets across the city-region.

Representation of the phy sical city of Leeds based, the contiguous built-up area

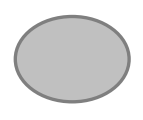

Representation of the local authority 'how we are gov erned' area
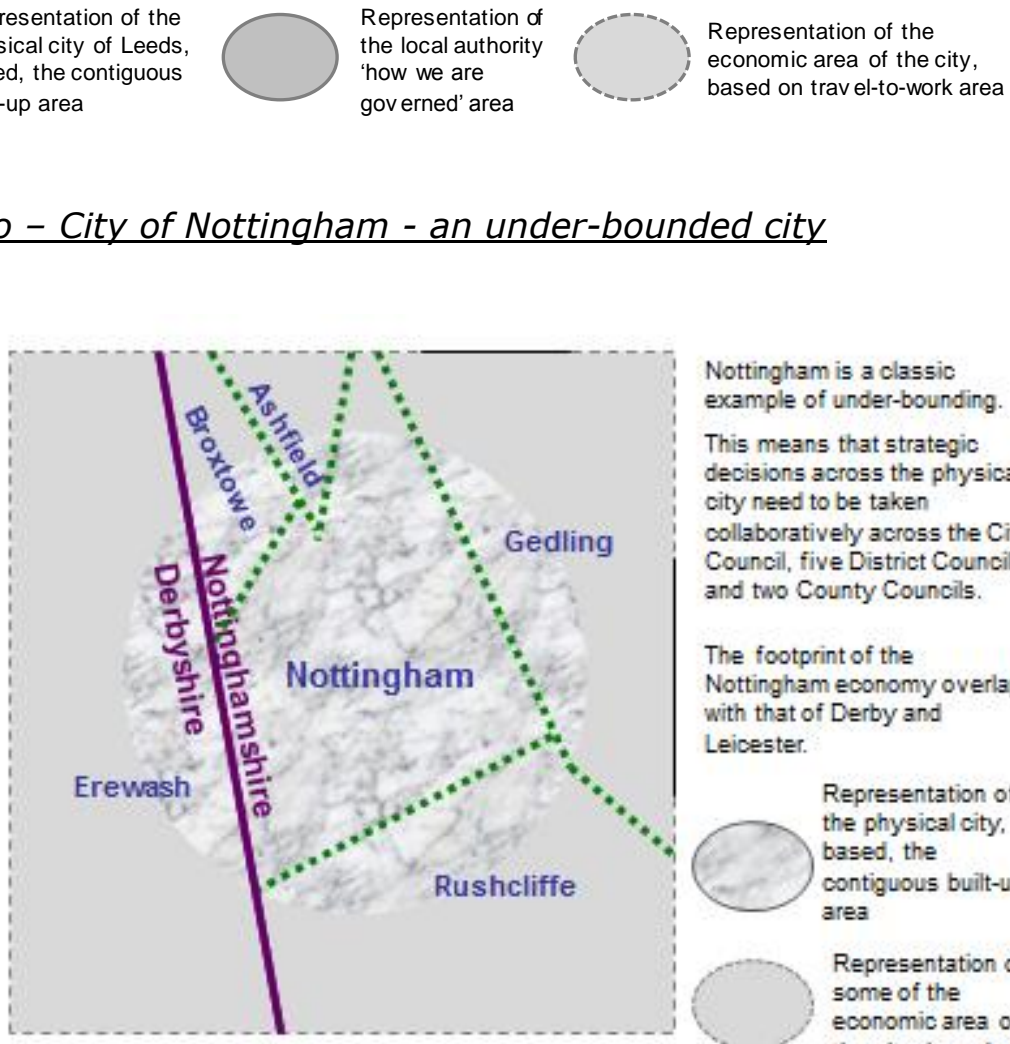

Nottingham is a classic example of under-bounding.

This means that strategic decisions across the physical city need to be taken collaboratively across the City Council, five District Councils and two County Councils.

The footprint of the Nottingham economy overlaps with that of Derby and Leicester.

Representation of the physical city.

based, the contiguous built-up area

Representation of some of the economic area of the city, based on travel-to-work area 


\footnotetext{
${ }^{8}$ Heseltine (2012) can anyway be criticised for example in terms of a failure to embrace multi-level governance and hence a genuine place-based smart-specialisation approach, or for really proposing an industrial policy for the regions (on the latter see Williams, 2012).
} 